Access to Justice in Eastern Europe,

Issue 2/3 (7) 2020

ISSN 2663-0575 (Print)

ISSN 2663-0583 (Online)

http://ajee-journal.com

10.33327/AJEE-18-3.2-3

C Popotas, 'COVID-19 and the Courts.

The case of the CJEU' (2020) 2/3(7)

Access to Justice in Eastern Europe 160-171.

10.33327/AJEE-18-3.2-3-n000033

\title{
COVID-19 AND THE COURTS. THE CASE OF THE CJEU ${ }^{* 1}$
}

\author{
Popotas Costas \\ Head of Unit, Statutory entitlements, \\ Social and Medical Affairs, \\ Working Conditions, Court of Justice of the EU, \\ PhD candidate, Ionian University, Luxembourg
}

Summary: 1. Introduction. - 2. Historical background. - 3. Preparedness and the COVID-19. - 3.1. Business continuity. - 3.2. Administrative adaptations. - 3.3. Access to the premises and hygienic measures. - 3.4. Working conditions. - 3.5. Medical issues. - 3.6. Revealed cases of COVID infections. - 3.7. Protocolary activities. 3.8. Communication. - 3.9. Safety and security. - 3.10. Interinstitutional coordination. 3.11. Jurisdictional issues. - 3.12. Caseflow at the Court. -3.13. Organisation of the Court Registry. - 3.14. General Court. - 3.15. General Court Registry. - 4. Conclusions.

Received: 03.09.2020. Revised: 07.09.2020. Approved: 08.09.2020

(C) 2020 Access to Justice in Eastern Europe and Costas Popotas.

This work is licensed under a CC BY NC ND 4.0 license.

This is an Open Access publication distributed under the terms of the Creative Commons Attribution 4.0 International License, which permits to copy and distribute the material in any medium or format in unadapted form only, for noncommercial purposes only, and only so long as attribution is given to the creator.

1 The note is based on the presentation, given him at the ,Online conference "The COVID-19 crisis - Lessons for the Courts', organized by EGPA Permanent Study Group XVIII ,Justice and Court Administration. See more at EPGA Study Group / K2 http://www.justizforschung. ch/index.php/homepage/egpa-study-group and EGPA Permanent Study Group XVIII ,Justice and Court Administration' https://egpa.iias-iisa.org/PSG_XVIII_JUSTICE_AND_COURT_ ADMINISTRATION.php\# 
The article describes the generally positive experience of Court of Justice of the European Union in managing the Covid-19 crisis. Before the outbreak of the Covid-19 crisis the Court had established an effective structure to cope with risks and issues related to pandemics. It benefited from an extensive migration to a modern computer operating system and the replacement of traditional desktop computers by portable devices capable of remotely connecting to the Court's network. Appropriate teleworking and extensive dematerialisation and simplification of standard administrative procedures took place and proved their effectiveness. The disruptive dimensions of COVID-19 pandemic forced the CJEU to accelerate transformations - not only digital but managerial and judicial processes The author analyses several phases of organising the functioning of the Court during the pandemic and comes to the conclusion that that the Court proved to be well prepared to tackle the issues raised by the COVID-19 pandemic. However, the quest of the future organisation will also have to do more with smart management and the new modes of working.

Keywords: Justice, Court Administration, COVID-19, CJEU.

\section{INTRODUCTION}

Just a year ago, Courts worldwide were navigating along their chosen pace in technological waters. Oscillating between the wish to be in the forefront of technology, or restrained by budgetary limitations, pandemics was a secondary issue in terms of technological planning. Since 2018 the big hype was about blockchain, the resuscitation of Artificial intelligence in law, predictive justice and the future of Courts. There has of course been the previous SARS and MERS alerts and jurisdictions had established continuity plans, untested of course under real circumstances, Courts thus remained confident that everything was accounted for and prepared adequately.

But COVID-19 has shifted Courts away from future perspectives and forced them to concentrate on the bitter realities of a crisis management situation. COVID-19 has put forth the value of proactive and good Court administration. The Court of Justice of the European Union (CJEU or the 'Court' henceforth) has luckily been preparing such an eventuality. The Court is a complex organisation with 2200 staff, two jurisdictions (the Court and the General Court), 91 Members (27 Judges, 11 Advocates General, 1 Registrar at the Court of Justice, 51 Judges and 1 Registrar at the General Court), a Multilinguism General Directorate covering translation and interpretation needs in all EU official languages and finally a relatively small administration, assisted by an inhouse medical service.

Ever since the 90's when a first crisis, around Asbestos fears, upset the services of the Court and ended to a massive removal of services outside the traditional premises, the Court has maintained a crisis management plan catering for all possible threats, including terrorism and pandemics. The plan gave ground to several drills on the one hand and, as far as pandemics were concerned, more specifically following the SARS and MERS concerns, led to detailed contingency plans and urgency structures to be activated in case such a threat materialised. Specific equipment was also acquired envisaging responses to safety requirements for staff that would be handling the CJUE core business during pandemics (personal protective equipment - masks and kits to cater for in case of emergency units had to operate). 
Thus the business continuity process at the Court, activated in response to the COVID-19 pandemic, largely based on the extensive teleworking arrangements put in place with effect from Monday 16 March, managed to guarantee the continuity of the judicial operations fundamental to the functioning of the European Union, entrusted to the jurisdictions.

\section{HISTORICAL BACKGROUND}

In a suitable timely preparation, the Court had established a structure to cope with risks and issues related to pandemics. The internal debates on previous occasions of anticipating on risks, resulted to the creation of two crucial committees, delegated with the task of supervising the activity of the Court in case of emergency: a) the Crisis unit, in the role of a strategic committee, regrouping high ranking officials and b) the crisis management committee (CMC), composed of representatives of operational services and the Registries, entrusted with the task of coordinating amongst the domains of activity of the Court in a rapid and flexible manner. Alongside these committees, operational cells within each service were expected to liaise with the coordination instances and implement the necessary measures within each service.

Even if no-one could imagine the extent of the problem and just before it became obvious that the cases of pneumonia in China represented a global threat, the Court had completed its preparedness. A happy coincidence wants that the CMC met in November and December in order to update the contingency plan with all emergency procedures in place, the business continuity plan and operational cells in all services.

More specifically, the CMC had been working throughout the previous years and as planned, on the 18th of December 2019, it established the infrastructure and operational procedures that would allow the members of the CMC to coordinate via the use of video-conferencing. All members of the committee were equipped with a laptop, capable of gaining remote access to their respective domains of activity and more importantly offering the possibility to hold virtual meetings. The committee was also given the capacity to send messages to the whole staff and Members of the institution via SMS, as well as to email both via the official addresses as well as the private ones. In January the whole setup was tested successfully.

Already, the Court, in the context of conciliation of work and family life, had established since 2004 a number of policies on working conditions that ended up contributing to a quick adaptation of the staff to the Covid-19 reality. In particular teleworking, that had been introduced long ago as a work pattern to conciliate work to family needs, which, towards the end of 2019, was adapted to cater also for occasional needs of remotely working. On a rotating basis, approximately $10 \%$ of the staff were at any moment homeworking. Several services and work profiles were allowed to practice by full or half time teleworking, and quite a number of colleagues have thus been trained to work at a distance while maintaining full productivity. Remote working was therefore nothing new for the Court. 


\section{PREPAREDNESS AND THE COVID-19}

When the COVID-19 started taking menacing dimensions in Europe, preparedness paid back. The Court activated timely its plan and considered the necessary adaptations, one week ahead of corresponding lockdowns decided by the National authorities. This reaction made, as will be explained later, that very few cases manifested at the Court and most importantly at the time they showed the risk of contamination through social contacts was minimised.

The Court benefited at this phase from an extensive migration to a modern computer operating system and the replacement of traditional desktop computers by portable devices capable of remotely connecting to the Court's network. Appropriate teleworking was thus effective for approximately $80 \%$ of the staff. The Court was at this time three months short of equipping the totality of its staff but shortly afterwards it managed to put in place an accelerated plan that equipped the rest by the end of May.

Extensive dematerialisation and simplification of standard administrative procedures took place during the week preceding the lockdown, and judicial procedures, which were at an advanced level of computerisation, were enhanced informatically. Internal and external communication were adapted and enhanced.

This way the Court managed to maintain its normal rhythm of deciding cases and publishing judgments. The number of cases resolved for the first quarter amounted to exactly the same as in 2019. In parallel, procedural measures compensated for the incapacity to hold hearings. Written questions to the parties replaced the debates that would normally take place in courtrooms. Deliberations amongst judges were in the first period conducted through written procedures via secure email, later replaced by secure videoconferencing.

Upon realisation of the risks that the new virus presented, a gradual adaptation to the new realities was taking place, following the advice of the medical service of the Court. Already in February, colleagues returning from areas that were heavily affected, were asked to self-isolate for two weeks.

Finally, following measures taken by Luxembourg, Germany, France and Belgium restricting movement of persons and sanitary limitations due to COVID-19 and in line with policies adopted by all other institutions, the Court, on the 13th of March adopted a generalised homeworking.

Several phases of organising the functioning of the Court were observed.

First phase of COVID-19 measures: 16 March to $24^{\text {th }}$ of May

The first phase that was announced on the $13^{\text {th }}$ of March and put in place as from the $16^{\text {th }}$ - later extended up to the $24^{\text {th }}$ of May. During that first phase, staff was invited to work remotely, while accesses to the Court premises were permitted for short periods, in view of dematerialising work or dealing with issues that could not be handled at a distance.

The CMC, having the delegations to oversee the coordination amongst services, continued virtually meeting during the remote work period once every two days in 
the beginning, but gradually the frequency was adapted to the everchanging realities. Several topics had to be dealt with, some of which are mentioned indicatively as follows.

\subsection{Business continuity.}

Remote working was preceded by a hectic preparation of such an eventuality. Fears of a generalised lockdown forced the services of the Court during the beginning of March 2020 to accelerate efforts to dematerialise the working support in administrative and judicial domains and convert paper-based workflows to electronically managed circuits.

\section{Informatics infrastructure}

The informatics department put in place an urgency plan in order to provide laptops to the members of staff that were not appropriately equipped. In parallel the network bandwidth was expanded in order to cope with the increased requests, due to both accesses to files and applications as well as for audio and videoconferencing. For the members of staff waiting for laptops to be made available, tokens or smartphones to allow remote access to webmail were given. Delivering the physical equipment, which gradually was completed by the $17^{\text {th }}$ of May, required of course special sanitary arrangements to guarantee social distancing and avoid contact between persons.

\subsection{Administrative adaptations.}

This novel situation brought forth the need for administrative adaptations never seen before, affecting all the Court's departments.

Important modifications took place at the core administrative level, reshuffling the traditional processes. In the first-place projects aiming at digitalising archives and services that had been pending for several years, were quite quickly implemented just before closure and allowed as from then to handle cases remotely. This was certainly also due to the lucky correlation that most administrative systems were at a level of maturity that allowed file handlers to work remotely as if they were at the office e.g. accounting, human resources, salary payment applications. Still several adaptations complemented the core systems to cater for areas where workflows were not previously dematerialised.

In all cases, the brief period just before the lockdown was a very intense one. New working methods had to be invented. From the simple alternatives permitting the online request for holidays through an external link - catering thus for people that wouldn't have direct access to the Court systems - up to the level of organising in a hurry a completely new service in order to issue certificates for colleagues that were obliged to cross borders in order to come to the Court - Luxembourg being a small country, many of the Court staff reside in the neighbouring countries, Germany, France, Belgium - therefore everything had to be adapted and tested while staff was still at the premises.

Access to the premises and hygienic measures.

As from the $13^{\text {th }}$ of March, entering the Court was rearranged dramatically. Beyond protective installations and personal protective means, entrance was subject to temperature checks and sanitary precautions to be taken. All visits were cancelled. 
Special protocols were also put in place for the cleaning and preventive disinfecting of spaces used.

Several diffuse problems made surface though. For example, the Court had already, as I said, an important stock of protective material (masks, disinfectants, gloves). But, since replacement had to be envisaged, the possibility to acquire new equipment was confronted with the intense competition and the limited availability of certified goods. The Court managed though to get hold of supplementary material allowing the possibility to gain almost normal activity for several months.

Attendance during restrictions

The Court has opted not identify critical/essential roles. Instead it entrusted line managers with the task of authorising staff to be present when needed.

Attendance at the Court was nevertheless limited. During the first phase very weak percentage of the staff $(1,5-2 \%)$ was present daily at the premises of the Court. The presence of service providers and staff in the buildings was only authorised for the performance of specific and necessary tasks.

\subsection{Working conditions.}

The peculiar situation of the staff being mostly expatriates had also to be accounted for. The Court's staff was of course concerned about family at their place of origin. Equally the social assistant had to take care of concerns of people in difficulties.

As for the working conditions, one victim of the new situation was flexitime - a facility provided to approximately $1 / 3$ of the staff in the pre-Covid period - which was suspended as unnecessary due to the remote working. Several adaptations of part time working were also registered.

\subsection{Medical issues.}

Another novel issue was the need for medical recommendations as the situation evolved. Beyond regularly issuing recommendations to the intention of $\mathrm{g}$ the $\mathrm{CMC}$, the Medical service established Protocols for tracing suspected and confirmed cases as well as close contacts which were rather successfully applied. Overall a number of 11 cases were revealed up to the 20th of April - none afterwards - and this is an indicator of how the system operated successfully in order to avoid recontamination. No disruption of the Court services and operations resulted from this occurrence.

Specific medical information was provided regularly through the communication channels, and a series of videos compiled by the in-house psychologist addressed issues relative to the stress produced by teleworking and related questions.

\subsection{Revealed cases of COVID infections.}

The Court has established fairly early a specific protocol for handling revealed cases of COVID-19 infections amongst Members or staff. In close contact with the Luxemburgish authorities, specifically designated medical and administrative instances were monitoring the cases concerned as well as their close contacts. Eleven cases were overall detected, a relatively small percentage of the staff. All necessary 
restrictions were applied and specific actions for decontaminating premises were undertaken. Data protection rules were previously adapted to be in line with the evolving situation, consequently tracking of the revealed COVID-19 cases and their contacts was established through operations conciliating respect of privacy and proper monitoring of health condition and risks.

The relatively small number of cases is an indicator of success of the surveillance policy and the timeliness of the social distancing measures.

\subsection{Protocolary activities.}

All protocolary activities were cancelled, the only residual activity concerned the swearing in of a newly appointed Member which was initially modified to require the smallest possible presence of people. Nevertheless, due to the evolving situation the taking of the oath of the new Advocate General took place via Skype, in the presence of the President of the Court, the First Advocate General and the Registrar.

\subsection{Communication.}

The Communication directorate had to reshuffle their communication strategy in order to adapt it to the current situation. Since the staff of the directorate was also asked to work remotely except upon specific request and planning, the directorate organised with the 2 registrars the modalities allowing, as far as possible, to carry out the authorization to publish delivered judgments and uploading press releases remotely and without the presence of people within the institution.

The Intranet and Internet sites were kept up to date by the Communication Desk in conjunction with the Office of the Registrar. Communication to the general public was adapted to be prepared remotely. In parallel the emergency procedures for internal communication were activated and Members and staff were constantly kept informed about ongoing and constantly changing conditions through a specific intranet page systematically updated, as well as, messages sent via SMS, official and private email.

\subsection{Safety and security.}

the Safety Unit was liaising with the Luxembourgish authorities and homologue services of other institutions in order to provide up to date information on adopted measures.

Cleaning and disinfecting

This operation gave rise to further adaptations of previous operations of cleaning and working in general, up to the level of adjusting facilities (door handles, lifts, photocopiers etc.).

\subsection{Interinstitutional coordination.}

All the EU institutions and agencies have adopted measures similar to the ones implemented by the Court. An inter-institutional network for information exchanges was set up under the aegis of CPQS, a specific Committee that is entrusted with preparing Heads of administrations decisions and to which the task of coordinating approaches amongst EU institutions was assigned. 


\subsection{Jurisdictional issues.}

The two jurisdictions adopted immediately the required adjustments of procedures and communicated them to concerned parties via email, as well as to potential parties via the web site of the institution and social networks. Very quickly, the week following the Court's "shutdown", measures meant to optimise the usage of resources were adopted by the presidents of the two jurisdictions:

\subsection{Caseflow at the Court}

All hearings and pleadings were postponed to a later date; 60 cases were considered urgent and one Urgent Preliminary Request was kept in progress for which the chamber has decided to waive the hearing and to put questions to the parties for written answers. Written procedures were put in place replacing the traditional deliberations.

- Deadlines remained as precised in the guidelines concerning the management of cases

- For all cases planned to be resolved without General advocate opinions (mostly cases of chambers at three judges) for which a hearing occurred already or was not considered necessary, the drafts of the judgments were handed as usual.

- For all cases planned to be resolved following a General advocate opinion for which a hearing occurred already or was not considered necessary, the drafts of the judgments started being prepared as soon as the opinion was handed down, in the language accessible by the chamber concerned.

(In all previous situations once the draft was handed down, deliberation of the chamber was immediately planned by written procedure, until a change of situation could allow face to face meetings.)

- For all cases for which an audience was already fixed the Court envisaged the possibility to replace the oral procedure by questions for written answers.

- For mature cases the normal route was followed by remote means, while in cases where the written procedure was still open the preparatory work was anticipated in order to facilitate future judicial considerations.

- For completed cases, sessions for grouped pronouncements of judgments were organised at specific dates respecting increased sanitary measures for judges and members of staff (e.g. interpreters) concerned.

\subsection{Organisation of the Court Registry}

Despite the increased digitisation of the judicial process, the Registry is still called upon to treat a relatively high number of acts of procedure which reach the Court by normal post. All relevant original documents and records, often bulky, have to remain securely at the Court and have to be digitised before they can be further processed. It was therefore necessary to establish new operative processes for the dematerialisation of documents in pending cases and, on the other hand, register, scan and treat all elements of procedure delivered to the Registry by normal post. Communication was at times difficult, in particular concerning request for 
preliminary ruling transmitted by national Courts which were not registered in the e-Curia application. To cope with this burden the Registry has organised brief visits at the Court buildings to operate the digitalisation, before transmission to services. In this way, the Registry has been able to perform a follow-up of all the cases received in the Court since the beginning of confinement, whether they were submitted electronically or by post.

On top of that, in the beginning of the confinement, not all of the staff at the Registry was in possession of equipment capable of remote access to business applications. Quickly, however, the Registry proceeded to address the main issues related to the core functioning of the jurisdiction. The majority of tasks were gradually catered for online, with the exception of the ones that require physical presence in the premises of the Registry and were thus deferred at a later date.

One of the problems that had to be tackled was the need to inform all parties involved in pending cases concerning the cancellation or postponement of hearings. Since some of the parties, especially in preliminary rulings cases do not have an e-Curia account and servicing by normal post was problematic, a lot of innovative spirit was invested in order to identify the contact details of parties and serve via email.

Finally, in order to meet with deadlines, all services involved shortened the time of treatment and readied their part of the work much earlier.

\subsection{General Court}

At the General Court the compulsory use of the e-Curia application by the parties facilitated the remote work of the Registry. It was thus possible to access remotely all of the filings, as well as the Registry was able to serve electronically all outgoing documents and acts of procedure, with the exception of acts to be served by post in extraordinary situation of parties not having an e-Curia account, for which dispatching was feasible only by being present at the Court.

However, the obligation to conserve an authentic paper version of the file of a case forces a backward compatible procedure for printing the corresponding files.

The deliberations were initially held by audio conferencing, quickly followed by video conferencing.

\subsection{General Court Registry}

The entire Registry has entered into a remote working regime as from the $13^{\text {th }}$ of March. Since teleworking was never implemented, the core of people equipped with laptops was the spearhead of the operation of the Registry in the beginning until total equipment allowing remote work was attained. The activity of the Registry has never stopped but has been reduced to the treatment of the more urgent cases.

Second phase: partial resumption of services, $25^{\text {th }}$ of May up to the $15^{\text {th }}$ of July

A partial resumption of activity occurred as from May 25, this up to the $16^{\text {th }}$ of July, The work plan for this partial resumption of activity on the site of the Court had been developed by the services of the Court well before the 25 May via three task forces entrusted with, 
respectively, the planning of hearings, the videoconferencing and finally security and health/ medical precautions to adopt measures in order to allow for gradual recovery of activity.

During this second phase more restrictive conditions of access to the Court's premises were introduced. Working at a distance remained the main rule. Entrance to the Court premises was allowed exclusively upon authorisation of the corresponding line manager and respecting the sanitary measures imposed. Staff having to be present at the Court had to abide by social distancing and wear masks outside individual offices.

The jurisdictions resumed hearings partially at a controlled rhythm. When to be held in situ, hearings were adapted to hygienic standards.

Distance Videoconferencing was put in place where attorneys could not be present for hearings, even if this could not be applied to complex cases (following the works of the taskforce "videoconferencing " and in the respect of the principles adopted by the committee "Rules of procedure " of the Court).

This hesitating exit from the previous almost complete halt of operations went very well, thanks to careful preparation work and to the efficient collaboration of all actors involved.

Reduced presence at the services, mainly the registries allowed to accomplish the tasks which could only be carried out in situ

Resuming the hearings obliged the services to organise in detail the new realities and involved a close coordination with all the Institution services principally concerned (directorates of interpretation, information technology, registry internal services. Precautions were taken as for the access to buildings and canalisation towards the courtroom concerned respecting social distancing, limited canteen facilities, distancing in the courtrooms and blocking of seatings, elimination of meeting with the parties prior to the hearing, even the possibility for party representatives to plead without gown if so wished.

The management of the hearings involved implementation of measures of organisation of the procedure aimed to verify the interest of the parties to attend a hearing. Indicatively, at the General Court , 69 plea hearings had been planned for the period from June 8 to July 15. After a difficult start during the week from 8 to 12 June with two hearings held out of the 14 scheduled, the return to a form of normality was noted as from the 15 June.

Third phase: judicial holidays ( $16^{\text {th }}$ of July up to the end of August)

The administration incited actively the staff to make use of their holidays. Since presences at the Court were by definition less numerous, measures were eased, leaving upon individuals to organise their presence at the Court, respecting always social distancing and sanitary precautions. Teleworking remained of course the principle.

Fourth period from $1^{\text {st }}$ of September onwards

At the end of the judicial holidays the Court had to clarify the applicable rules. In order to conciliate business continuity with the preservation of people's health, it was decided to maintain the generalised remote working. Anew, access to the Court's premises will be organised as it was during the second phase, subordinating it to the 
authorisaton of line managers for as long as it is necessary for the execution of tasks requesting physical presence mostly related to hearings. Social distancing and health precautions remain compulsory.

Luxembourg has put in place a systematic possibility to undergo free COVID-19 tests for residents returning from holidays abroad. Nevertheless the Court decided to offer the possibility of tests to a limited number of persons performing essential functions requesting physical presence at the Court.

\section{CONCLUSIONS.}

The need to consolidate and accelerate the digital transformation

The disruptive dimensions of COVID-19 pandemic forced the CJEU to accelerate transformations - not only digital but managerial and judicial processes also. Procedural, organisational, communication, security, sanitary protection measures were adopted or adapted, to cater with the new realities. In a matter of weeks, the Court has put in place developments that would have required years of work. Important administrative decisions have been immediately adopted following the CJEU lockdown taking into consideration the capacity of the services, the priorities of the jurisdictions without losing from sight the staff needs. Delegations and replacements were organised in time. Finally, the CJEU has demonstrated the resilience it was expected to have established through years of preparation.

With the first hindsight that the passage of time allows, the management of the crisis can be viewed positively, even if the challenge is to predict when the crisis will end and what has to be kept from the forced transformation of the CJUE administration.

Given the exceptional circumstances of the COVID-19 crisis and of the business continuity mode, the administration of the Court has been effective since it remained operational and continues essential functions until relative normality is re-established.

One of the main conclusions we can draw is that COVID-19 has hindered normal everyday relations amongst persons but were partially replaced by intense communication and the use of technological tools. But on the other hand, staff became more autonomous, and even if dematerialisation was a question of individual reorganisation to begin with, convergence of practices and bringing together of experiences became an asset.

In general, the crisis seems to have strengthened the links between the services. Exchanges in within the Center of management of crisis (CMC), have allowed for these services to better understand their needs and to work very effectively together. This was proven by a Satisfaction Survey that was launched by the Staff representation Committee and demonstrated a strong support for the measures taken.

Overall, it can be said that the Court proved to be well prepared to tackle the issues raised by the COVID-19 pandemic. But most importantly what can be seen in this preparation is that in reality the Court's authorities prepared their staff to prepare the change and to embrace it. There was a generalised solidarity and investment in converting each one's tasks in the new context. If it is true that in the beginning everybody was hopeful that 
the crisis would end in the summer, it became in the meanwhile obvious that plans had to be extended on a longer period.

For the services that were already on the route of computerising their records and workflows, Covid-19 has not made access to services more difficult. In terms of quality of service, in reality internal users have not noticed a substantial difference of access to applications compared to the previous situation.

But post COVID-19 everything will be different, changes will be broad, deep and lasting. The challenge for the CJEU now is of course to master the new dynamics, maintain and improve all positive changes and leapfrog to the post COVID era, redesigning and modernising processes and projecting the justice system in the digital age, in cybersecure environment, while guaranteeing access to justice for the European citizens and appropriate working conditions for its staff.

It is obvious that this pandemic is going to modify radically and profoundly the workings of the Court in the future, in particular, since the persistence of the crisis was an unprecedented challenge. What the future holds is relatively unclear. This is obviously not just going to force to amend the informatics tools. Procedural rules are going to follow the new organisational methods, simplify the approach and certainly provide for delegated acts that could adapt to the evolution of similar crises. Adaptation will be needed in all areas including communication and formal exchanges. for certain the COVID-19 crisis has shifted things also towards modernising the administration of justice at the Court. The need for simplification, flexibility, less formalism, the quest for integrated systems accessible to habilitated users without intermediaries, the use of remote conferencing/virtual hearings and the inspiration from online Courts ideas are now on the table. The crisis is alleviating resistance to change, accelerating digital transformation. And there is no way back.

But since we speak in terms of administration, the quest of the future organisation will also have to do more with smart management and the new modes of working in which all persons involved will have to be trained in the alternative modes of operation and collaboration, get familiarised with new ways of bonding within services and the new responsibilities in management reinforced. 